\title{
КОММЕРЧЕСКИЕ ОРГАНИЗАЦИИ В ГРАЖДАНСКОМ КОДЕКСЕ ВЕНГРИИ
}

МЕРКУЛОВА Тамара Александровна, старший научный сотрудник Центра сравнительно-правовых исследований Института законодательства и сравнительного правоведения при Правительстве Российской Федерации

117218, Россия, г. Москва, ул. Большая Черемушкинская, 34

E-mail: foreign3@izak.ru

Статья посвящена формам совместной коммерческой деятельности. Положения о формах коммерческой деятельности содержатся в книге 3 «Юридические лица» Гражданского кодекса Венгрии, который вступил в силу в марте 2014 г. Гражданский кодекс Венгрии не предусматривает деление юридических лиц на коммерческие и некоммерческие. Проведенный автором анализ позволил из содержащегося в Кодексе перечня организационно-правовых форм выделить такой вид, как юридические лица, осуществляющие деятельность в целях получения прибыли. Формами таких юридических лиц являются хозяйственные товарищества, кооперативы, объединения и группы предприятий. В статье излагаются общие положения, которые распространяются на все организационно-правовые фрормы коммерческой деятельности, а также правила, относящиеся к отдельным фрормам и видам коммерческих юридических лиц. Значительное место отведено в статье хозяйственным товариществам и их видам, а именно простым товариществам, коммандитным товариществам, товариществам с ограниченной ответственностью и акционерным обществам. В статье нашли отражение новеллы Гражданского кодекса Венгрии, касающиеся отдельных коммерческих организаций. Так, согласно новому Гражданскому кодексу правом юридического лица наделены простые товарищества и коммандитные товарищества. Кроме того, Гражданским кодексом введена новая форма сотрудничества организаций, осуществляющих коммерческую деятельность, которая получила название «группа предприятий».

Ключевые слова: Гражданский кодекс Венгрии, юридическое лицо, предприятие, объединение, товарищество, общество, коммерческая организация, корпорация, реорганизация, правовой статус, кооператив, взнос, прибыль, акция, устав, имущество, слияние, реестр, правовое положение, управление.

\section{COMMERCIAL ORGANIZATIONS IN THE CIVIL CODE OF HUNGARY}

T. A. MERKULOVA, senior research fellow of the Centre of comparative law researches of the Institute of Legislation and Comparative Law under the Government of the Russian Federation

34, Bolshaya Cheremushkinskaya st., Moscow, Russia, 117218

E-mail: foreign3@izak.ru

The article is about the forms of joint commercial activities, contained in Book 3 "Legal Entities" of the Civil Code of Hungary, which came into force in March, 2014. The Code does not divide legal entities into commercial and non-profit organizations. On the basis of the analysis of the list of legal forms of commercial organizations the author distinguishes legal entities, whose activities are aimed at receiving profits. These forms are: business partnerships, cooperatives, business combinations and groups of enterprises. The article describes general conditions, which are typical for all forms of commercial legal units. The article pays much attention to business partnerships and their types, such as simple partnerships, limited partnerships, limited liability partnerships and joint - stock companies. The article describes some important changes in the field of commercial legal entities. For example, according to the Civil Code of Hungary simple partnerships and limited partnerships are vested with the right of legal entities. Besides, the Civil Code introduces a new for the Hungarian legislation form of commercial activities between organizations which is called a group of enterprises.

Keywords: Civil Code of Hungary, legal entity, enterprise, company, partnerships, commercial organization, corporation, reorganization, legal status, cooperative, share, profit, statute, property, mergers, register, legal situation, administration.

DOI: $10.12737 / 17109$

B ступивший в силу в 2014 г. новый Гражданский кодекс Венгрии ${ }^{1}$ (далее - ГК) содержит немало интересных новелл, в том числе касающихся коммерческих организаций, которые считаются в стране основными субъектами экономического оборота.

Книга 3 «Юридические лица» ГК не предусматривает деления юридических лиц на коммерческие и некоммерческие, а дает перечень их организационно-пра-

${ }^{1}$ Cм.: Magyar közlöny. 2013. No. 31.

вовых форм, из которого коммерческие организации можно выделить исходя из их существенного признака - осуществления деятельности в целях получения прибыли. Такими организационно-правовыми формами можно считать хозяйственные товарищества, кооперативы, объединения и группы предприятий.

Хозяйственные товарищества. Хозяйственные товарищества представляют собой форму коллективной хозяйственной деятельности, правовое регулирование которой берет начало с принятия в 1875 г. Закона о торговле, определившего, в частно- 
сти, условия и порядок создания акционерных обществ и товариществ с ограниченной ответственностью. Действовавший более 100 лет нормативный акт был отменен только принятым в 1988 г. первым Законом «О хозяйственных товариществах»², в котором был закреплен перечень строго определенных форм предпринимательства, решен вопрос о наделении юридических лиц гражданской правосубъектностью.

Второй Закон «О хозяйственных товариществах» ${ }^{3}$ был принят в 1997 г., когда в результате общественноэкономических преобразований и стремлений привести законодательство страны в соответствие с законодательством Европейского Союза в стране была существенно обновлена нормативная база. В 2004 г. Венгрия была принята в члены Европейского Союза. В целях приведения законодательства страны в соответствие с решениями органов Европейского Союза в 2006 г. был разработан третий Закон «О хозяйственных товариществах» ${ }^{4}$, закрепивший принцип замкнутого перечня форм хозяйственных товариществ - существуют только формы, определенные в этом Законе.

В новый ГК включены общие нормы, касающиеся хозяйственных товариществ, а также регулирующие отдельные виды этих товариществ. Новеллой ГК является в том числе расширение количества форм коммерческих организаций, пользующихся правом юридического лица - таким правом теперь наделены простые и коммандитные товарищества. Вместе с тем со значительными изменениями продолжает действовать третий Закон «О хозяйственных товариществах». Следовательно, можно сказать, что в отношении системы регулирования хозяйственных товариществ в Венгрии действует двухуровневая система законодательства.

Общие положения о хозяйственных товариществах. Хозяйственные товарищества определяются ГК как наделенные правом юридического лица предприниматели, учрежденные для ведения совместной коммерческой деятельности с использованием предоставленных их участниками имущественных взносов и на условиях совместного участия в прибылях и убытках. В общих положениях о хозяйственных товариществах определяются порядок их создания, система руководящих органов и условия прекращения их деятельности.

Гражданский кодекс допускает создание строго определенных форм хозяйственных товариществ, наделенных правом юридического лица: простое и коммандитное товарищества, товарищество с ограниченной ответственностью и акционерное общество. Правовой основой деятельности хозяйствен-

\footnotetext{
${ }^{2}$ Cм.: Magyar közlöny. 1988. No. 92.

${ }^{3}$ Cм.: Magyar közlöny. 1997. No. 114.

${ }^{4}$ Cм.: Magyar közlöny. 2006. No. 1.
}

ного товарищества признается документ о его создании, который оформляется в виде договора, учредительного документа или устава. Независимо от выбранной организационно-правовой формы хозяйственного товарищества документ о его создании должен содержать сведения о наименовании и местонахождении товарищества, о порядке управления его деятельностью, прочие данные, установленные как обязательные для данного товарищества. Гражданский кодекс не определяет круг лиц, которые могут быть членами хозяйственного товарищества, но предусматривает ограничения для участия отдельных субъектов гражданского права в его деятельности. Так, физическому лицу разрешается одновременно быть участником только одного товарищества с ограниченной ответственностью, а несовершеннолетнее лицо, простое и коммандитное товарищества не могут быть членами такого товарищества.

Необходимое для деятельности хозяйственного товарищества имущество предоставляется учредителями в виде денежных и неденежных взносов. В качестве неденежного взноса может выступать любое не изъятое из оборота имущество, в том числе имущественные права. Хозяйственное товарищество приобретает права и принимает на себя обязанности через органы управления, обеспечивающие руководство деятельностью товарищества. По способу приобретения полномочий руководящие органы товарищества могут быть подразделены на выборные и назначаемые. Порядок их избрания или назначения определяется законом и документом о создании хозяйственного товарищества.

Образование хозяйственного товарищества завершается его регистрацией, которую осуществляет суд, ведущий реестр фирм. В процессе регистрации суд проверяет законность создания товарищества, соблюдение им требований, предписанных законом.

Общие положения ГК о хозяйственных товариществах не предусматривают детальных норм о преобразовании, объединении, разделении и прекращении товарищества без правопреемства, а содержат отсылку к соответствующим общим нормам о юридических лицах, которые устанавливают для хозяйственных товариществ возможность реорганизации и прекращения без правопреемства. Реорганизация проводится путем слияния, присоединения, выделения и преобразования. В случае реорганизации имеет место относительное прекращение деятельности хозяйственного товарищества с сохранением его имущества для использования в гражданском обороте или с переходом его прав и обязанностей к другим лицам в порядке правопреемства. Прекращение хозяйственного товарищества без правопреемства происходит по следующим основаниям:

по истечении срока, на который создавалось хозяйственное товарищество; 
при наступлении условий, которые оговаривались как основание для прекращения хозяйственного товарищества;

согласно решению, принятому членами или учредителями хозяйственного товарищества;

в соответствии с решением о ликвидации хозяйственного товарищества, вынесенным правомочным органом.

В общих положениях о хозяйственных товариществах содержатся нормы о преобразовании одной формы товарищества в другую, об объединении хозяйственных товариществ и их преобразовании в кооперативы.

Общую характеристику основных признаков хозяйственного товарищества сформулировал венгерский ученый Тамаш Шаркези в работе «Статутное право организаций в новом Гражданском кодексе» ${ }^{5}$. По мнению автора, хозяйственное товарищество:

обладает организационным единством, имеет самостоятельный правовой статус, отдельный от правового статуса учредителей, определяемый учредительными документами, на основании которых хозяйственное товарищество создается, регистрируется и осуществляет свою деятельность;

располагает обособленным имуществом, которое предоставляется ему для самостоятельного хозяйствования и должно быть обособлено от имущества учредителей и участников;

несет самостоятельную имущественную ответственность, отвечая по своим долгам только собственным имуществом.

Изложенные выше положения ГК о хозяйственных товариществах только в общем виде закрепляют их организационно-правовую структуру. Для более детального ознакомления рассмотрим каждую форму хозяйственных товариществ, выяснив особенности их возникновения и функционирования.

Простое товарищество. Простым считается товарищество, участники которого в соответствии с заключенным между ними договором берут на себя обязанности по предоставлению имущества, необходимого для осуществления совместной коммерческой деятельности товарищества, а также по несению неограниченной и солидарной ответственности по обязательствам, для погашения которых недостаточно имущества товарищества. Важной новеллой ГК в отношении простого товарищества следует считать его признание юридическим лицом. Тем самым было устранено действовавшее в законодательстве противоречие, касавшееся положения простого товарищества, в соответствии с которым оно рассматривалось как самостоятельный хозяйствующий субъект, ведущий совместную коммерческую деятельность, но при этом не пользующийся правом юридического лица.

${ }^{5}$ См.: Sarközy T. Szervezetek status jogaazuj RTK-ban. Budapest, 2013.
Имущество, необходимое для деятельности простого товарищества, предоставляют его участники в виде взносов, а управление его деятельностью основано на принципе единогласия всех участников. При этом каждый член полного товарищества имеет одинаковое с остальными участниками количество голосов. Ведение дел простого товарищества обеспечивается одним или несколькими администраторами, которые могут выбираться или назначаться. Когда избрания или назначения администратора не происходит, его функции вправе выполнять любой член простого товарищества.

Из числа установленных ГК прав и обязанностей членов простого товарищества следует выделить их право на участие в прибылях, полученных в результате ведения хозяйственной деятельности, и обязанность участвовать в погашении возникшей задолженности. Член простого товарищества наделен также правом уступки полагающейся ему доли участия в прибылях другому члену товарищества или третьему лицу. В целях реализации такого права заключается письменный договор и вносятся соответствующие изменения в договор товарищества. Следует упомянуть также о праве члена простого товарищества на выход из него. Указанное право не может быть ограничено или аннулировано, если простое товарищество создано на неопределенный срок. В целях защиты интересов остающихся членов простого товарищества покидающий его участник обязан предупредить о своем выходе из товарищества за три месяца.

Кроме общих для всех хозяйственных товариществ оснований прекращения правоотношений с ними ГК устанавливает следующие случаи прекращения таких правоотношений, касающихся простого товарищества: по общему согласию членов простого товарищества, а также в связи с отказом, заявленным членом простого товарищества, с уступкой доли участия в прибылях товарищества, со смертью члена товарищества или его прекращением.

Коммандитное товарищество. Такое товарищество наряду с простым товариществом относится к организационно-правовым формам коммерческой деятельности. Своеобразие коммандитного товарищества состоит в том, что оно объединяет две группы участников - полных товарищей и коммандитистов. Полные товарищи обеспечивают управление всеми делами товарищества, но при этом они несут неограниченную ответственность по его обязательствам. Коммандитисты же практически не участвуют в управлении товариществом, но и риск их ограничивается размерами взносов в имущество товарищества.

Коммандитное товарищество создается на основании договора, в котором его участники берут обязательство осуществлять совместную коммерческую хозяйственную деятельность. Выбытие кого-либо из 
полных товарищей или из коммандитистов приводит к прекращению деятельности коммандитного товарищества. Исключение составляют случаи, когда в течение шести месяцев оставшиеся члены товарищества заявляют осуществляющему регистрацию суду о своем намерении создать вместо ранее существовавшего товарищества простое товарищество или новое коммандитное товарищество. В этих целях они вносят изменения в договор товарищества, которые фиксируются в реестре регистрации фирм. В целом правовой статус коммандитных товариществ определяется теми же положениями, что и правовой статус простого товарищества.

Товарищество с ограниченной ответственностью. Таким товариществом признается хозяйственное товарищество, уставный капитал которого состоит из заранее определенных размеров взносов и участники которого не несут ответственности по его обязательствам, а рискуют только своими взносами. Для создания товарищества с ограниченной ответственностью его участники заключают между собой договор товарищества, в котором кроме обязательных общих положений указываются также размеры взносов, подлежащих внесению отдельными участниками, и данные о праве голоса в зависимости от внесенных средств.

Имущественной базой для деятельности товарищества с ограниченной ответственностью является уставный капитал, который состоит из денежных и иных имущественных взносов, предоставленных его участниками. Гражданский кодекс предусматривает минимальный размер уставного капитала, необходимого для успешной деятельности товарищества (3 млн форинтов). При этом взносы отдельных членов товарищества могут быть разной величины, но не менее 100 тыс. форинтов. Каждому члену товарищества разрешается делать только один имущественный взнос, но при этом у одного взноса может быть несколько собственников.

Товарищество с ограниченной ответственностью возникает после его внесения в реестр регистрации фирм. С регистрацией товарищества права его участников и их доли в имуществе выражаются в паях. Номинальная стоимость пая конкретного члена товарищества зависит от его взноса в уставный капитал. При этом ни один член товарищества не может иметь больше одного пая, но у одного пая может быть несколько владельцев. В соответствии с ГК пай в товариществе с ограниченной ответственностью может быть объектом различных сделок. Так, Кодекс разрешает свободную уступку пая другим членам товарищества. Для отчуждения пая третьему лицу необходимо, чтобы уступающий пай член товарищества в полном объеме выполнил свои обязательства по предоставлению взноса. Любая сделка, связанная с уступкой пая, оформляется в виде письменного договора. При этом к приобретающе- му в результате уступки пая лицу переходят как все права, так и все обязанности, вытекающие из правоотношений членства в товариществе с ограниченной ответственностью.

Наряду с основаниями прекращения, установленными общими нормами о хозяйственных товариществах, в отношении товарищества с ограниченной ответственностью предусмотрено его прекращение без правопреемства. В этом случае действует следующий порядок раздела имущества товарищества: в первую очередь удовлетворяются претензии кредиторов, а оставшаяся часть имущества делится между членами товарищества пропорционально их взносам.

Акционерное общество. Гражданский кодекс определяет акционерное общество как хозяйственное товарищество, уставный капитал которого разделен на заранее установленное число акций предусмотренной номинальной стоимости и риск участников которого ограничивается размерами их взносов в уставный капитал. Акционерное общество создается и действует в форме открытого или закрытого общества. Открытым признается общество, акции которого допускаются к обращению на бирже, в то время как акции закрытого акционерного общества не могут обращаться на бирже. В этом заключается одно из основных различий между открытым и закрытым акционерными обществами.

Как и другие хозяйственные товарищества, акционерное общество обладает уставным капиталом, который формируется за счет средств, поступивших от акционеров в виде платы за приобретаемые акции, и определяется как капитал, состоящий из совокупной номинальной стоимости всех акций акционерного общества. Гражданский кодекс устанавливает минимальный размер уставного капитала для закрытого (не менее 5 млн форинтов) и для открытого (не менее 20 млн форинтов) акционерных обществ.

Уставный капитал акционерного общества разделен на доли, выраженные в акциях, которые определяются как именные, имеющие номинальную стоимость ценные бумаги, удостоверяющие членские отношения их эмиссионеров с акционерным обществом. Выпускаемые акционерным обществом акции могут быть простыми, привилегированными, акциями для работников, процентными и выкупаемыми.

Простыми считаются акции, не относящиеся ни к одному из перечисленных выше видов товариществ. Обязательным условием выпуска простых акций является соблюдение оговоренной общей номинальной стоимости акций, которая должна составлять больше половины уставного капитала акционерного общества.

Привилегированные акции обеспечивают преимущества по отношению к другим видам акций. Они издаются на условиях, определенных в уставе акционерного общества. 
Акции для работников могут быть бесплатными и льготными. Они являются именными и могут передаваться только лицам, состоящим с обществом в трудовых отношениях. В случае прекращения трудовых отношений работник утрачивает право на владение акциями и уступает их акционерному обществу. Если работник умирает, его акции уступаются акционерному обществу его наследниками. При невыполнении обязательства по уступке акций для работников общее собрание акционерного общества выносит решение об изъятии таких акций из обращения или об их преобразовании в другой вид акций.

Уставом акционерного общества может быть предусмотрен выпуск процентных акций на сумму, не превышающую $10 \%$ уставного капитала акционерного общества. Держатель процентной акции пользуется всеми правами, полагающимися акционерам, а также правом на проценты, выплачиваемые за счет балансовой прибыли акционерного общества за год.

Выкупаемые акции могут приобретаться акционерным обществом на сумму, не превышающую $20 \%$ уставного капитала общества. В отношении выпущенных выкупаемых акций акционерное общество приобретает право покупки и продажи, а акционеры - только право продажи. Все акции регистрируются в книге акций с указанием имени и адреса владельца, количества и вида принадлежащих ему акций. Книгу акций ведет правление каждого акционерного общества.

Создавая акционерное общество, его участники разрабатывают устав, в котором помимо общепринятых обязательных реквизитов должны содержаться сведения об уставном капитале, о количестве выпускаемых акций, их номинальной стоимости, способе эмиссии и изготовления. Кроме того, в уставе указываются перечень обязательств, взятых учредителями в отношении эмиссии акций, правила их распределения среди учредителей, а также порядок созыва общего собрания акционеров и данные о главном бухгалтере акционерного общества. Создание акционерного общества завершается его регистрацией, которую проводит председатель суда, ведущего реестр регистрации фирм.

Высшим органом управления акционерным обществом является общее собрание его участников, которое решает вопросы, отнесенные к его исключительной компетенции, и созывается с периодичностью, определенной в уставе акционерного общества, но не реже одного раза в год. Функции исполнительного органа акционерного общества выполняет правление, состоящее из трех физических лиц, которые выбирают из своего состава председателя. Отличие установлено для закрытого акционерного общества, устав которого может предусмотреть отказ от избрания правления и передачу исполнения его обязанностей генеральному директору. В свою очередь, устав открытого акционерного общества может содержать положение о том, что управление акционерным обществом обеспечивается советом директоров, состоящим из пяти физических лиц, замещающих правление и контрольную комиссию. Согласно правилам о контрольной комиссии она должна быть избрана в открытом акционерном обществе. Закрытое акционерное общество создает контрольную комиссию, если соответствующее ходатайство заявляют $5 \%$ членов общества, имеющих право голоса.

В соответствии с нормами ГК в открытом акционерном обществе должна создаваться аудиторская комиссия, которая избирается общим собранием. Аудиторская комиссия решает такие задачи, как оказание содействия контрольной комиссии, совету директоров в проверке системы финансовых отчетов, в выборе кандидатуры на должность бухгалтера.

Прекращение акционерного общества может быть осуществлено с применением соответствующих общих норм о хозяйственных товариществах, а также действующих положений о преобразовании, объединении или разделении акционерного общества. Решение о преобразовании принимает общее собрание акционерного общества. Положительное решение о преобразовании акционерного общества не означает прекращения имеющихся у него обязательств, например, перед кредиторами, работниками, но при этом акции преобразуемого акционерного общества становятся недействительными.

Кооперативы. Как и хозяйственные товарищества, кооперативы являются коммерческими организациями. Следует отметить, что кооперативы издавна занимают одно из ведущих мест в аграрном производстве Венгрии. Как указывал еще в 1970-х гг. ученый Д. Чанади, кооператив в качестве организационной формы хозяйственной деятельности возник в середине XIX в. как попытка защиты мелких собственников. По мнению ученого, такие кооперативы не могли играть важной роли в хозяйственной деятельности по сравнению с крупными капиталистическими производствами, но они обеспечивали членам кооператива определенные преимущества в области оптовых закупок и реализации продукции ${ }^{6}$.

Важное значение для развития кооперативного движения имел Гражданский кодекс 1959 г., который включал понятие кооператива и вводил новый институт кооперативной и личной собственности․ Нормы Гражданского кодекса 1959 г. получили развитие в Законе «О сельскохозяйственных производственных кооперативах» 1967 г., в соответствии с которым все земли (кроме приусадебных участков) становились предметом общей хозяйственной деятельности. Кроме того, устанавливались обязательство кооператива по обеспечению занятости и обязанность членов

\footnotetext{
${ }^{6}$ CM.: Csanadi G. Polgari Jog. Budapest, 1973.

${ }^{7}$ Cм.: Magyar közlöny. 1959. No. 78.
} 
кооператива участвовать в трудовой деятельности ${ }^{8}$. В период проведения в стране реформы хозяйственного механизма был принят Закон «О кооперативах» 2006 г., отдельные положения которого действуют и в настоящее время.

Гражданский кодекс Венгрии определяет кооператив как юридическое лицо, образованное с капиталом, состоящим из предоставленных его участниками имущественных взносов, и осуществляющее деятельность в соответствии с принципами открытого членства и переменного капитала. Общие нормы ГК о кооперативах позволяют образовывать кооперативы отечественным и иностранным физическим и юридическим лицам, устанавливая при этом определенные ограничения. Так, ограничивается общее количество юридических лиц и хозяйственных товариществ без права юридического лица - членов кооператива, которые должны составлять не более $50 \%$ от общего количества членов кооператива. Число членов кооператива, на которых не распространяется обязанность личного участия в его деятельности, не должно превышать 1/4 от общего количества членов кооператива.

Учредительным документом кооператива является его устав, для принятия которого необходимо единогласное волеизъявление не менее семи участников. Разработанный устав подписывает каждый член кооператива. Кроме обязательных сведений, которые должны содержаться в документе о создании юридического лица, устав кооператива определяет цели его организации, размер и порядок предоставления имущественного взноса, формы участия членов кооператива в его деятельности, органы управления кооперативом и условия выхода из него. Деятельность кооператива может осуществляться после его внесения в реестр регистрации фирм. Гражданский кодекс предоставляет кооперативам право на ведение любой не запрещенной законом деятельности, направленной на удовлетворение потребностей его участников.

Характерной особенностью кооператива является достаточно широкое участие членов кооператива в управлении, реализуемое прежде всего через общее собрание - высший орган управления делами кооператива. Оно созывается не реже одного раза в год или по требованию не менее $10 \%$ членов кооператива либо контрольной комиссии. Исполнительным органом кооператива является правление, состоящее не менее чем из трех членов кооператива. И правление, и его председателя избирает общее собрание на пятилетний срок. Правление самостоятельно определяет регламент своей деятельности, руководит работой кооператива и представляет его в отношениях с третьими лицами. Кроме того, оно правомочно

\footnotetext{
${ }^{8}$ Cм.: Magyar közlöny. 1967. No. 82

${ }^{9}$ CM.: Magyar közlöny. 2006. No. 1.
}

принимать решения по всем вопросам, которые закон или устав не относит к компетенции общего собрания кооператива или его контрольной комиссии.

В целях осуществления внутреннего контроля финансово-хозяйственной деятельности кооператива его общее собрание избирает контрольную комиссию в составе трех членов кооператива на пятилетний срок. Для ведения надлежащих, отвечающих нормам Закона о бюджете учета и отчетности общее собрание кооператива на пятилетний срок избирает бухгалтера, которым может быть лицо, зарегистрированное в соответствии с нормой Закона в качестве бухгалтера. Функции бухгалтера не вправе выполнять член кооператива и его органа руководства, а также их ближайшие родственники.

Гражданский кодекс предусматривает возможность преобразования и прекращения деятельности кооператива. Преобразование кооператива может быть проведено путем объединения и разделения, если с такой инициативой выступают не менее $10 \%$ членов кооператива или его правление. Кроме того, кооператив может быть преобразован в товарищество с ограниченной ответственностью или в закрытое акционерное общество. Что касается прекращения деятельности кооператива без правопреемства, то основанием для этого является сокращение численного состава членов кооператива (меньше семи участников) и отсутствие в течение шести месяцев заявлений от новых кандидатов, желающих вступить в члены кооператива.

Объединение. Гражданский кодекс определяет объединение как наделенное правом юридического лица кооперационное товарищество, созданное его участниками для содействия успешному хозяйствованию и координации хозяйственной деятельности, а также для представительства профессиональных интересов.

Объединение как институциональная форма кооперационных связей известно венгерскому праву с конца 1960-х гг. Такие объединения создавали предприятия, другие социалистические организации на договорной, добровольной основе исходя из общих экономических интересов, а также в целях согласования совместной деятельности. При этом предусматривалась возможность создания объединения и по указанию отраслевого министра. В этом случае объединение образовывалось на срок до пяти лет, а его участники во исполнение указания министра заключали между собой договор.

После смены общественного строя, произошедшей в 1990-х гг., в стране применяется гражданскоправовое регулирование создания кооперационных связей - используется правовая форма договора товарищества. Одним из принятых в последнее время нормативных актов, определяющих правовое положение объединений, является ГК, в соответствии с которым кооперационные связи лиц, учреждающих 
объединение, могут устанавливаться с использованием общих норм о товариществах.

Создание объединения основывается на заключении договора товарищества, в котором кроме положений, обязательных для включения в учредительный документ, определяются задачи, ставящиеся перед объединением; порядок распределения между членами объединения затрат в связи с ведением хозяйственной деятельности; суммы взносов, уплачиваемых отдельными членами объединения; условия возврата имущества члену объединения в случае его выхода; порядок раздела имущества при прекращении деятельности объединения.

Регулируя имущественные отношения между объединением и его участниками, ГК устанавливает для членов объединения возможность безвозмездного пользования услугами, которые оказываются объединением. Прибыль, получаемая объединением по результатам хозяйственной деятельности, распределяется между его участниками пропорционально их имущественным взносам. Оставшаяся после распределения часть прибыли делится среди членов объединения поровну.

В целях выработки и выражения своей воли объединение образует соответствующие органы. Высшим органом объединения является общее собрание его участников, которое созывается не реже одного раза в год и правомочно принимать решения, если присутствует не менее 3/4 представителей членов объединения, имеющих право голоса. Ведение дел и представительство интересов объединения обеспечивает директор.

По решению общего собрания членов объединения оно может быть прекращено, преобразовано, а для участия в нем может быть принято любое лицо. В связи с преобразованием объединения применяются соответствующие нормы права о товариществах. Что касается вступления в объединение новых участников, то решение об этом принимает общее собрание, руководствуясь условиями, определенными в договоре товарищества.

Группа предприятий. Новеллой ГК является регулирование в рамках самостоятельного раздела такого вида отношений между рыночными субъектами, как группа предприятий. Венгерский ученый К. Пизманди ${ }^{10}$ сравнивает группы предприятий с действовавшими в 1960-е гг. крупными предприятиями, которые создавались в венгерской промышленности в процессах кооперирования и специализации производства. Основное различие между крупными предприятиями и группами предприятий автор усматривает в том, что крупные предприятия образовывались на основе добровольного соглашения, которое заключалось только между предприятиями, в то вре-

\footnotetext{
${ }^{10}$ См.: Pazmandi K. Konszernrendelkezesekesvallalatcsopor travonatkozoszabalyozas. Gazdasagesjog, 2011|7—8. O. 24-29.
}

мя как в состав группы предприятий могут входить акционерные общества, товарищества с ограниченной ответственностью, объединения, кооперативы.

Гражданский кодекс рассматривает группу предприятий как сотрудничество организаций, осуществляющих коммерческую деятельность. При этом Кодекс прямо не определяет статус группы предприятий. По мнению венгерского ученого Т. Шаркези, изложенному в статье «Положения нового Гражданского кодекса об объединениях и благотворительных фондах $)^{11}$, несмотря на то что нормы о группах предприятий изложены в разделе о юридических лицах, эти группы нельзя считать юридическими лицами, такими лицами являются только члены этих групп.

Кодекс устанавливает следующие условия, которые обязаны соблюдать юридические лица, создающие группу предприятий: в составе группы должно быть не менее одного господствующего и трех контролируемых участников; каждый член группы предприятий готовит консолидированный годовой отчет о своей деятельности с соблюдением норм Закона о бухгалтерском учете; группа предприятий создается на основании доминирующего договора, в котором определяется единая коммерческая политика этой группы. Статус группы предприятий приобретается ею после регистрации судом, ведущим реестр фирм. Основанием для регистрации является заявление, поданное администратором господствующего члена группы. Члены группы предприятий остаются юридическими лицами, но имеют общее руководство, осуществляемое господствующим членом группы предприятий. Отношения между господствующим и контролируемыми членами группы предприятий строятся в соответствии с положениями доминирующего договора. При этом договор может установить право администратора господствующего члена группы предприятий давать указания контролируемому члену группы предприятий, а также принимать решения, которые контролируемые члены группы предприятий обязаны выполнять в ходе осуществления своей деятельности. Администраторы как господствующего, так и контролируемых членов группы предприятий должны не реже одного раза в год представлять отчеты о своей деятельности, связанной с выполнением договорных обязательств.

При ликвидации кого-либо из контролируемых членов группы предприятий господствующий член группы предприятий несет ответственность за удовлетворение требований кредиторов. Исключение составляют случаи, когда неплатежеспособность контролируемого члена группы предприятий не является следствием мероприятий, проводимых группой предприятий в целях осуществления единой коммерческой политики.

${ }^{11}$ См.: Szarközy T. Szervezetek jogallasaazuj Ptk-ban // Gazdasages Jog, 2011|3. O. 3-8. 


\section{БИБЛИОГРАФИЧЕСКИЙ СПИСОК}

Csanadi Gy. Polgari Jog. Budapest, 1973.

Magyar közlöny. 1959. No. 78.

Magyar közlöny. 1967. No. 82.

Magyar közlöny. 1988. №. 92.

Magyar közlöny. 1997. No. 114.

Magyar közlöny. 2006. No. 1.

Magyar közlöny. 2013. No. 31.

Pazmandi K. Konszernrendelkezesekesvallalatcsoportravonatkozoszabalyozas. Gazdasagesjog, 2011| 7-8.

Sarközy T. Szervezetek status jogaazuj RTK-ban. Budapest, 2013.

Szarkozy T. Szervezetek jogallasaazuj Ptk-ban // Gazdasages Jog, 2011|3.

\section{REFERENCES}

Csanadi Gy. Polgari Jog. Budapest, 1973.

Magyar közlöny. 1959. No. 78.

Magyar közlöny. 1967. No. 82.

Magyar közlöny. 1988. №. 92.

Magyar közlöny. 1997. No. 114.

Magyar közlöny. 2006. No. 1.

Magyar közlöny. 2013. No. 31.

Pazmandi K. Konszernrendelkezesekesvallalatcsoportravonatkozoszabalyozas. Gazdasagesjog, 2011|7—8.

Sarközy T. Szervezetek status jogaazuj RTK-ban. Budapest, 2013.

Szarkozy T. Szervezetek jogallasaazuj Ptk-ban // Gazdasages Jog, 2011|3. 